Fecha de recepción: abril 2020

Fecha de aceptación: mayo 2020

Versión final: junio 2020

\section{Encontros com a Civilização Brasileira e Coleção Primeiros Passos: edição, política e democracia no Brasil (1979-1985). \\ Andréa Lemos ${ }^{(1)}$}

Resumo: Os espaços culturais criados pelas editoras brasileiras, comprometidas com o processo de retomada das condições democráticas no Brasil, em fins da década de 1970 e início dos anos 1980, foram muito além do rigor nas escolhas de autores, temas e novos formatos de livros em seus catálogos. Ao construírem meios de ampliar a participação política da intelectualidade brasileira em novos espaços culturais ao final da ditadura civilmilitar, editores como Caio Graco Prado (editora Brasiliense) e Ênio Silveira (editora Civilização Brasileira) deram continuidade às suas práticas político-culturais de resistência ao regime militar e de intervenção no processo formativo de um público leitor interessado em uma maior politização.

Palavras chave: História Editorial - Coleções - Editores brasileiros - Democracia - Redemocratização - Resistência - Caio Graco Prado - Ênio Silveira.

[Resumos em espanhol e inglês na página 143]

(1) Doutora (2009) e Pós-Doutora (2012) em História pela Universidade Federal Fluminense. Professora Adjunta de História do Departamento de Ciências Humanas e Filosofia do Instituto de Aplicação Fernando Rodrigues da Silveira (Cap-UERJ), atuando na educação básica e na licenciatura de História. Pesquisadora colaboradora do Núcleo de Documentação Memória e História (UniRio/CNPq); membro do Laboratório de Ensino de História (LEH-Cap/UERJ). Tem experiência de pesquisa na área de História do Brasil Republicano e Ensino de História.

Os espaços culturais criados pelas editoras brasileiras, comprometidas com o processo de retomada das condições democráticas no Brasil, em fins da década de 1970 e início dos anos 1980, foram muito além do rigor nas escolhas de autores, temas e novos formatos de livros em seus catálogos. Ao construírem meios de ampliar a participação política da intelectualidade brasileira em novos espaços culturais ao final da ditadura civil-militar, editores como Caio Graco Prado e Ênio Silveira deram continuidade às suas práticas político-culturais de resistência ao regime militar e de intervenção no processo formativo de um público leitor interessado em uma maior politização ${ }^{1}$. 
O universo intelectual brasileiro nesse contexto passava por uma série de reformulações, com as quais os editores se filiavam. Foi o momento de ascensão do movimento dos trabalhadores, operário e sindical, fundamentalmente, que vinha se organizando ao longo do regime militar e que em fins da década de setenta garantiu seus espaços de representação política, alterando a direção do processo de abertura democrática que ocorria de "cima para baixo", quando surgiam ainda diversos movimentos sociais que incrementavam a luta pelo fim da ditadura.

A intelectualidade brasileira atenta a esse novo cenário reconhece ainda as inúmeras greves que desde 1978 ganhavam organicidade nacional por meio da formação de dois blocos de sustentação de caráter intersindical, os chamados "sindicato autêntico" e "unidade sindical". O primeiro constituído por sindicalistas metalúrgicos do ABC paulista, "novo sindicalismo"2 e com futura adesão do Partido dos Trabalhadores (PT) em 1980, formavam o chamado bloco "combativo". Segundo Marcelo Badaró Mattos (2002), o "novo sindicalismo" reivindicado pelos autênticos era aquele de ruptura com a estrutura sindical e do vínculo com o Estado, bem expresso nas palavras do presidente do sindicato dos metalúrgicos à época, Luis Inácio Lula da Silva (Lula):

...É preciso acabar com a contribuição sindical que atrela o sindicato ao Estado. A estrutura e a legislação sindical deveriam ser reformuladas como resultado das necessidades. $\mathrm{O}$ sindicato ideal é aquele que surge espontaneamente, que existe porque o trabalhador exige que ele exista (Lula, citado por Mattos, 2002, p. 79).

E o segundo bloco combativo era constituído por lideranças tradicionais do movimento sindical, considerado um setor mais conservador denominado de "pelego" e de militantes da esquerda "tradicional" como Partido Comunista Brasileiro (PCB), Partido Comunista do Brasil (PC do B), Movimento Revolucionário (MR-8) ${ }^{3}$. Ainda que intencionassem formar apenas uma central sindical as oscilações dos dois blocos deu origem a duas centrais em 1980: a Central Única dos Trabalhadores (CUT) e a Coordenação Nacional da Classe Trabalhadora (CONCLAT), substituindo, respectivamente, as denominações dos blocos “combativo" e "pelego". Segundo Marco Aurélio Santana (2003), em 1983 criou-se a Coordenação Nacional da Classe Trabalhadora, seguindo em muito a orientação do PCB, ainda com objetivo de não criar uma central sindical, por isso "coordenação", para evitar a divisão do movimento. Mas em 1986 diante da previsão de não realização da unidade devido às divergências entre as centrais e o avanço da CUT, aquela Coordenação passa a ser uma central sindical, denominada Central Geral dos Trabalhadores (CGT). Em 1988 passa a Confederação Geral dos Trabalhadores (CGT) e, desde 1991, Força Sindical. Outro acontecimento relevante daquele contexto foi a formação do Partido dos Trabalhadores (PT), que ocorreu no desdobramento dos movimentos de trabalhadores e de ampliação dos espaços de participação política do conjunto da sociedade brasileira. Entre os diversos setores que articularam a fundação do partido encontravam-se "sindicalistas, membros da igreja católica (CEB's, pastorais, etc), organizações de esquerda (trotskistas), intelectuais e alguns parlamentares oriundos do MDB" (Rozentino, 2000, p. 158). Mesmo com essa diversidade de setores que integrou sua formação, a "construção de um partido 
dos trabalhadores significava a quebra da hegemonia burguesa, que se exercia sobre todas as forças oposicionistas através do MDB” (Gurgel, 1989, p. 68).

Além de assumirem uma posição política declaradamente a favor da democracia no Brasil, os editores destacados neste artigo utilizaram seus meios editoriais para incrementar tais discussões políticas da época aderindo às mobilizações democráticas, inclusive partidárias. Analisamos neste artigo o conjunto das ações políticas em torno da publicação da Coleção Primeiros Passos pela editora Brasiliense, sob a direção de Caio Graco Prado, e da coleção Encontros com a Civilização Brasileira, publicada pela editora Civilização Brasileira, dirigida por Ênio Silveira, quando esses empresários da cultura construíram diferentes caminhos no processo de redemocratização em curso.

\section{Coleção Encontros com a Civilização Brasileira; Centro Brasil Democrático e o Partido Comunista Brasileiro nas ações de Ênio Silveira}

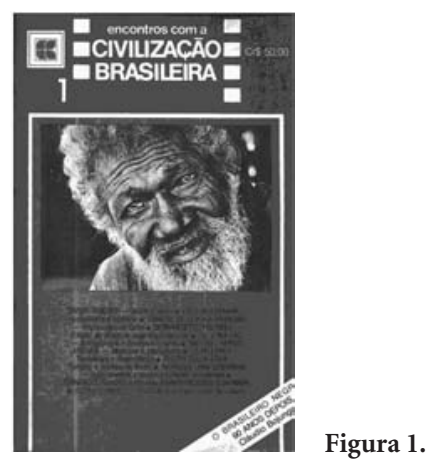

A coleção Encontros com a Civilização Brasileira foi uma das últimas publicações periódicas de relativo sucesso da Editora Civilização Brasileira na abertura democrática. A análise dos editoriais dessa publicação permitiu identificar a perspectiva crítica de seu projeto cultural, assim como o debate político incentivado pela editora, na última gestão de Ênio Silveira como proprietário.

A coleção Encontros apresentava artigos de conteúdo político e foi publicada entre 1978 e 1982, com total de 29 volumes, dirigida por todo tempo de sua existência por Ênio Silveira e Moacyr Felix. Não havia uma divisão temática, como sua antecessora a Revista Civilização Brasileira ${ }^{4}$, por vezes um assunto ou uma obra era evidenciado em vários artigos. Era composta em seu conjunto por artigos originais e resenhas críticas de obras recémlançadas, assim como de livros estrangeiros ou nacionais já consagrados. 
Apesar da Editora Civilização Brasileira não ser a editora do Partido Comunista Brasileiro (PCB) ela também publicou artigos de autores que eram membros ou simpatizantes do partido nessa época. Moacyr Félix, poeta, membro do Partido, também organizador da coleção Encontros com a Civilização Brasileira, foi o autor que mais publicou artigos e resenhas, com um total de 18 artigos. Ao longo dos anos de publicação dessa Coleção, entre 1978 e 1982, os autores, com algumas exceções, não se repetiram com muita freqüência.

Os resultados da análise de toda coleção mostram, a exceção dos editores, que autores como Ignácio Rangel, Nelson Werneck Sodré, Leandro Konder, Darcy Ribeiro, Frei Beto e Carlos Nelson Coutinho foram aqueles que mais publicaram ou que fizeram maior sucesso. O caso mais destacado ocorreu em um artigo deste último autor, intitulado "A democracia como valor universal", em 1979, estabelecendo-se como referência central do debate promovido na "Encontros". Entretanto, a autoria que mais se repetiu foi de Ênio Silveira. Os textos de Ênio Silveira retratavam os assuntos próprios do processo político brasileiro da abertura democrática. Em todos os editoriais, Ênio Silveira partia de uma análise mais geral para enfrentar um ponto da situação atual do país. O editor sempre fazia uma sugestão e expunha sua visão sobre a conjuntura.

No editorial de abertura do lançamento da "Encontros com a Civilização Brasileira" ela foi definida como uma coleção de livros com previsão de lançamento mensal, constituindose de "artigos, ensaios e notas de crítica, assinados por colaboradores nacionais e estrangeiros que, pelo seu não-sectarismo, contribuirão para a abertura de horizontes, os atos de pensar e repensar o mundo em que o homem luta" (Silveira, 1978, p. 7).

A expectativa do editor em relação ao lançamento estava diretamente ligado ao sucesso da Revista Civilização Brasileira nos anos 60. Segundo ele,

Encontros com a Civilização Brasileira, uma coleção de livros aberta a todas aquelas tendências que a evolução do pensamento social e científico vem configurando como a atual e plurificada face do humanismo contemporâneo. (...). Em linhas gerais, como se pode ver, a coleção Encontros ... mantém -e ampliaa linha de conduta intelectual que, de 1964 a 1968, cercou de tanto apreço a Revista Civilização Brasileira ${ }^{5}$.

Logo no segundo editorial ${ }^{6}$ intitulado "Fazer História ou não, eis a opção", expunha-se a proposta de uma publicação claramente comprometida com o processo político em curso, quando o editor explicita sua visão sobre aquela conjuntura. Os objetivos da coleção ECB defendidos na apresentação do primeiro volume começam aqui a se realizarem por seus dois editores.

Nesse editorial, Ênio Silveira escreveu sobre a candidatura de João Batista Figueiredo à presidência com críticas dirigidas diretamente à expectativa da eleição indireta para presidência da república. Já o texto de Moacyr Felix tem um perfil distinto, oferece ao leitor, por meio de outra abordagem, o caráter político que Ênio Silveira imprimiu nos primeiros números da Coleção. O editor-chefe da "Encontros com a Civilização Brasileira" defendeu ao longo desse texto a idéia de que a temática dos artistas não precisavam se caracterizar como engajadas para que esses mesmos artistas definissem suas posições políticas como 
cidadãos. Apresentou assim seus argumentos combatendo uma visão que limitava o papel do artista ao conteúdo estritamente político. Em suas palavras:

Em épocas como esta, em que estão ameaçados e atingidos os valores mais urgentemente ligados à existência, a poesia como instrumento de luta social se exacerba e se emerge, e a isso deve ser estimulada, para o primeiro plano. Em épocas assim, é natural que a função da poesia se desloque prioritariamente para outras razões de ser que não somente aquelas que lhe deram origem. Exigir de um artista ou de um poeta, no entanto, que o seu poema ou a sua música apareçam exclusivamente engajados na temática assim dita social, isso é uma besteira, um erro, uma deformação dos próprios fins a que esta exigência, em ultima análise, se diz atrelada. Toda obra de arte é engajada, quando é verdadeiramente uma obra de arte; e isso porque ela é participante do impulso básico do ser humano para a liberdade, ou seja, para a beleza da vida. O que se pode, em épocas de crise, é indagar ao poeta ou ao artista, mas enquanto cidadãos, por uma solidária definição de caráter político. Caso contrário não vamos mais nem entender o quanto de humano persiste, vibra, e se movimenta, intelectual e emocionalmente, nas cantigas de roda, ou nas canções folclóricas de amor e de infância e de solidão e de trabalho, que estão presentes na história de todos os povos. As existências e as lutas do homem se situam em vários planos da luta de classes, planos que não podem ser desligados, que se interpenetram uns nos outros e se fundem na formação de um tempo histórico global, que é o do seu passado, o do seu presente e, importantíssimo, o do seu futuro, o do seu devenir ${ }^{7}$.

Ao reivindicar a politização do poeta como cidadão, e não necessariamente em sua produção artística, Moacyr Felix revela um debate caro à época com relação ao engajamento ideológico nas artes em geral, que marcou a intelectualidade brasileira durante o regime militar. Devido as diferentes formas de resistências no campo cultural terem apresentado significativas participações artística e intelectual, principalmente no período imediatamente após o golpe de 64, as análises posteriores sobre o papel do cinema, do teatro, da música, da literatura, das artes plásticas, da imprensa escrita, da televisão e da universidade foram amplamente estudadas e suas reflexões se estenderam para a década de 70, contextualizando a forte opressão do regime sobre a intelectualidade em oposição. No quadro político da década de 70, muitos intelectuais se reuniram em busca de criar formas de intervenção política, ainda que num cenário limitado pelo regime, reforçando a necessidade de manter a elaboração crítica da conjuntura como uma das estratégias de oposição. Debates próprios daquela conjuntura nas artes e na política em torno da consciência cidadã, reivindicada por Felix, foi mais uma vez apresentada no editorial seguinte. $\mathrm{O}$ texto era uma transcrição pouco alterada de um escrito do próprio autor em 1961 na Suécia e publicado no Brasil em 1965, que ele retoma para mostrar, por meio do poema, e na condição de editor-chefe "como (se dá) o fazer político do intelectual através da ação cultural que lhe é própria”. 
Ainda ao final do governo Geisel, no último editorial do ano de 1978, Ênio Silveira discorreu sobre o resultado das últimas eleições favorável para o $\mathrm{MDB}$, em tom de protesto às tentativas do governo de apagar essa "vitória", pois

O MDB por tudo o que seja, ou apesar daquilo que não seja, venceu esmagadoramente em quase todos osgrandes centros urbanos, em todos os locais onde a máquina repressiva e coercitiva do Governo, posta sem disfarce a serviço da ARENA, não conseguiu agora, como ocorreu em outros períodos eleitorais transcorridos sob a ditadura, decidir a parada com tranqüilidade?

Defendia que a diferença de cinco milhões de votos era bastante significativa para passar sem uma reflexão. Para o editor essa vitória representava uma "vantagem tática obtida com a conquista de importante cabeça de ponte democrática" ${ }^{10}$. Concordava com a posição cautelosa de Ulysses Guimarães sobre tal vitória que "não se deve, nos quartéis oposicionistas, iniciar a arrancada da reorganização partidária antes que condições objetivas a ensejem, ou até determinem"11. Ênio afirmou que naquele momento as

Facções diversas de oposição ao governo, dentro e fora do MDB, intensificaram seus preparativos para reorganizar em termos partidários a vida política nacional, como se a liberdade, gloriosa e refulgente, já tivesse efetivamente aberto suas asas sobre nós... ${ }^{12}$.

Ao contrário da afirmação do editorial anterior, onde Ênio Silveira exaltou o resultado das eleições contra a tentativa de obscurecimento da vitória do MDB pelo governo, em editorial seguinte, Ênio Silveira criticou o entusiasmo dos setores progressistas com os resultados das eleições para o Congresso, lembrando-os da permanência não declarada da ditadura, tendo em vista que seus representantes viam naquele resultado, somado a volta do pluripartidarismo, um caminho aberto para as oposições em geral, como na criação de um outro partido de oposição.

Além disso, o editor explicitou sua visão sobre a situação do novo presidente eleito quanto à necessidade de se construir algum tipo de diálogo com a democracia. Apontou os riscos que João Baptista Figueiredo corria no processo "se (sua vitória) não for dedicada ao povo e por ele aclamada com espontâneo entusiasmo"13. O editor reivindicou que fosse promovido um "desenvolvimento que não seja milagroso e beneficie apenas a um pequeno grupo de privilegiados e às empresas multinacionais a que cada um deles, com maior ou menor recato, presta vassalagem, mas a todos nós, que somos seu legítimo destino"14.

O espaço da Revista divulga visões sobre a conjuntura com objetivo de dialogar com o leitor, afirmando ser expressão do anseio de "todos nós". O editor explicita que, no entanto, estava se construindo de "cima para baixo" sob a direção do novo presidente, no mesmo projeto de governo originado do processo de abertura política desde meados de 1970. Assinala por fim que o

O General João Batista Figueiredo, se não quiser tapar o sol com a peneira deve ter bem presente que nada de efetivo conseguirá realizar, em termos de 
governo, se mantiver enquadrado na rígida e estéril estrutura de poder que um grupo integrado por elementos minoritários das Forças Armadas e do empresariado, tem imposto tanto à Nação como a seus dirigentes ${ }^{15}$.

O grupo minoritário do empresariado mencionado por Ênio diz respeito ao empresariado vinculado ao capital multinacional e associado, apresentado por René Dreifuss (1964: A Conquista do Estado) como os co-agenciadores da ditadura militar, cuja participação foi progressiva na direção política econômica ao longo do regime, mesmo diante das rearticulações em seu interior. Ênio Silveira reclama uma ampliação dos grupos no poder a partir de 1979 que venham a representar os interesses da "nação" e de seus "dirigentes". Em sua recusa a um esquema que a seu ver deveria ser rompido, o editor encerra as últimas linhas fazendo menção direta ao presidente defendendo a restauração do estado de direito e a implantação da democracia.

Em momento de grande mobilização da classe trabalhadora, Ênio Silveira ao omitir de seu discurso as greves, que explodiam naqueles anos iniciais da publicação, e defender como missão do presidente o retorno do Estado democrático, traduzia a "luta democrática" reivindicada pelo PCB: a defesa da Anistia, das eleições e da Constituinte reforçando a unidade da oposição.

A concepção de que as reivindicações das massas estariam representadas na direção política e não na base do processo expressa ainda esse "pecebismo", o qual até este momento de sua trajetória como editor, se mantivera assumidamente separado de suas publicações. A coleção "Encontros" é a única de seus lançamentos em que o editor explicita sua filiação ao posicionamento do PCB. Os temas principais apontados pelo editor Ênio Silveira no conjunto de seus editoriais podem ser agrupados em: expectativas sobre o governo Figueiredo; modelo econômico e Assembléia Nacional Constituinte, enfim, a luta pela institucionalidade democrática, expressando as orientações políticas do partido para o período. Entretanto, o conjunto dos artigos publicados na Encontros são diversificados, mantendo a abertura crítica que defendia.

Além de abrir espaço de debate político em uma publicação organizada pela editora e lançar autores nacionais e internacionais, Ênio Silveira atuava na formação de algumas organizações/instituições que reivindicavam um caminho democrático naquela conjuntura. Ainda na condição de militante pela democracia e envolvido com o PCB, Ênio Silveira teve sua atuação investigada pela polícia política do Rio de Janeiro. O material apreendido pelo DOPS-RJ que destacamos neste artigo caracteriza esta sua participação política quando fundou o Centro Brasil Democrático (CEBRADE). Bastante conhecido pelo grande número de adesões de artistas e intelectuais ao seu programa ${ }^{16}$ na época e por algumas de suas famosas ações culturais, tais como o show do Riocentro, no qual houve o episódio de explosão de uma bomba, pelos militares, em $1981^{17}$, o CEBRADE teve como fundadores: Oscar Niemeyer, Sergio Buarque de Holanda, Antonio Houaiss e Ênio Silveira.

Segundo matéria do jornal O Globo de 30/07/78 selecionada pela polícia, o CEBRADE, criado no dia anterior, sob a presidência de Oscar Niemeyer, era definido como "uma instituição sem finalidade político-partidária que congregará personalidades de vários estados interessadas em discutir os problemas do país"18. Em seu "Projeto de Programa de Trabalho" para aquele ano estava enunciado como objetivos principais "a defesa dos 
direitos humanos, (...) assim como a discussão e a difusão de idéias e projetos de institucionalização democrática da vida pública brasileira" ${ }^{19}$. Para melhor verificarmos como tais objetivos foram realizados, nos baseamos nos documentos da polícia política quando das investigações a respeito do funcionamento do CEBRADE, ainda com intuito de caracterizar os espaços de atuação do editor e qualificar seu papel militante.

De início, a polícia mostrou a relação entre os que apoiaram o Manifesto de Fundação do CEBRADE com aqueles que atuaram no extinto Comando Geral dos Trabalhadores Intelectuais $^{20}$ (CGTI), evidenciando a continuidade da ação de intelectuais comunistas. Entre eles estavam arquitetos, jornalistas, escritores, editores, teatrólogo como: Oscar Niemeyer, Ênio Silveira, Barbosa Lima Sobrinho, Carlos Scliar, Dias Gomes, Flavio Rangel, Franklin de Oliveira, João Antônio, Joaquim Pedro de Andrade, Nelson Werneck Sodré e Osny Duarte Pereira.

Esses intelectuais deram representatividade ao CEBRADE cujo projeto de democratização visava cumprir um "papel sério e destacado na vida brasileira" ${ }^{21}$ e iniciar as "mudanças profundas na organização institucional e social no país"22.

A documentação policial considerava que o CEBRADE tinha os mesmos princípios do PCB quando se tratava de "classe operária". Esta conclusão se baseia "na cartilha do PCB"23 que apresentou como tarefa principal do Partido "educar a classe operária, organizá-la e dirigi-la em suas lutas de cada dia, preparando-a e conduzindo-a para a revolução socialista"24. Explicitam idéias do livro O que fazer de Lênin, apresentado como argumento principal para tal objetivo. No resumo da polícia sobre o livro consta que

O nível de consciência da classe operária faz com que ela chegue espontaneamente, apenas à luta por uma política sindical, economista, a fim de lograr objetivos imediatos; todavia, para que esta classe operária possa manifestar todo o seu potencial político, torna-se necessários que os intelectuais, oriundos de outras classes sociais, inspirem e eduquem a classe operária na consciência de sua missão política, como vanguarda a força motriz da revolução. Isto porque os operários não tem tempo nem capacidade de elaborar uma teoria política em bases científicas. Esta tarefa caberia aos intelectuais, que se encarregariam da educação, organização, agitação e propaganda ${ }^{25}$.

Ao contrário da interpretação da polícia, as atividades do CEBRADE vinculadas aos sindicatos de trabalhadores (trabalhadores agrícolas, metalúrgicos, indústria petroquímica, indústria de couro e peles, bancários, petróleo, energia elétrica, médicos e jornalistas) denotam a concepção de seu projeto quanto ao papel da sociedade civil no processo, porém, numa perspectiva mais pluralista.

Os intelectuais dirigentes ${ }^{26}$ do CEBRADE criavam atividades conjuntas com outros movimentos políticos e sociais, como ocorreu também com o Comitê Brasileiro pela Anistia. Foram organizados encontros nos quais se definiam as ações a empreender.

O principal aspecto deste movimento pode ser exemplificado pela valorização das organizações de base. Como resultado do Encontro Nacional pela Democracia, ainda em 1978, época de sua fundação, definiu-se como princípio que as organizações de base 
são os instrumentos que se contrapõem à tentativa de elitizar a vida política e o processo decisório; são o traço de ligação entre partidos e povo, entre político e povo, entre as partes do povo; é nelas que devem inspirar-se os quadros políticos; ficou bem clara a profunda necessidade de uma mobilização democrática constante, sempre vinculada às organizações e associações de base; concentrar os esforços num programa mínimo: anistia (hoje já alcançada) e Constituinte ${ }^{27}$.

A organização de shows de música popular brasileira no Riocentro tinha um caráter beneficente. A renda do show de 1979 com campanha pela Anistia, por exemplo, destinava-se ao Encontro Nacional de Líderes Sindicais que ocorreu no mesmo ano. Desse Encontro foi elaborada a Carta do Gragoatá, por ter ocorrido neste bairro em Niterói, na qual estavam expostas as principais conclusões das lideranças sindicais presentes:

É essencial para os trabalhadores a plena e integral restauração das liberdades democráticas: de imprensa, de expressão, livre associação e organização partidária"; consideram indispensável a liberdade e a autonomia sindicais, o direito de greve e a estabilidade no emprego, convertidos em princípios constitucionais que venham a ser aprovados em Assembléia Nacional Constituinte; exortam os assalariados das diversas categorias para que, através da sindicalização e da organização nos locais de trabalho, fortaleçam os sindicatos que, no processo de luta pela conquista da autonomia e liberdade sindicais, deverão ser coordenados por uma Central Única dos Trabalhadores; defendem a livre organização partidária; incentivam a participação do Sindicato em todas as ações de massa ${ }^{28}$.

A Anistia destacada como meta para o CEBRADE foi tema de outros eventos promovidos por seus dirigentes, tais como: Ato na sede da Associação Brasileira de Imprensa (ABI), em 1979, quando "jovens angariavam fundos em prol da Frente Sandinista de Libertação" da Nicarágua; manifestações públicas na Cinelância pela Anistia (mas também pelas liberdades sindicais e contra cassação do MDB); delegações para promover a volta dos exilados. Em 1980, o CEBRADE elaborou um relatório de auto-avaliação de suas funções desde sua criação, no qual os intelectuais concluíram:

A existência do Cebrade foi um fator positivo no avanço registrado pelas correntes democráticas; no Encontro Nacional pela Democracia foi indubitável a melhor definição de uma estratégia comum das forças de oposição que ali se conseguiu; o Encontro Nacional de Dirigentes Sindicais proporcionou uma forte demonstração de unidade e solidariedade proletária no esforço nacional de conquista das liberdades democráticas e deu ensejo a uma definição mais qualificada das reivindicações do movimento operário na luta pelo regime democrático; a realização do show 1 de maio foi também importante, como forma de arrecadação de fundos e como forma de expressão unitária da solidariedade dos artistas para com as aspirações do povo trabalhador; poderá firmar-se numa vigorosa tradição brasileira; as seções estaduais (em Brasília, 
MG, Rio Grande do Sul, São Paulo e Pernambuco) desenvolveram atividade intensa e profícua.... ${ }^{29}$

Em 1980, há referência sobre a intenção do CEBRADE de tornar o show um ato tradicional, este assunto foi grifado pela polícia. Um ano depois ocorreu a explosão da bomba. $\mathrm{Na}$ época, segundo texto da polícia, os "agentes do DOI/I Exército foram vítimas de um atentado terrorista" ${ }^{\prime 0}$. Em 1980, também houve show em $1^{\circ}$ de maio com renda prevista para CONCLAT, que a policia chama equivocadamente de Congresso Nacional das Classes Trabalhadoras.

Entre outras atividades promovidas pelo CEBRADE ainda podemos citar: palestras realizadas na Academia Brasileira de Imprensa e Universidade Santa Úrsula dentro de um "ciclo de debates" organizado junto com UEE-RJ. Nessa palestra houve participação de Luis Carlos Prestes e Marcelo Cerqueira sendo mencionados pela polícia como "notórios comunistas de sempre"; implantação da Unidade Interdisciplinar do CEBRADE (UNIBRA$\mathrm{DE}$ ), que funcionava como um "instrumento de trabalho com a juventude" sobre o qual o próprio CEBRADE reivindicava da seguinte maneira: "as evidentes carências do ensino regular torna ansiosa por fontes alternativas mais aptas de formação cultural" ${ }^{31}$. Por meio da UNIBRADE se realizou, no Teatro Clara Nunes, o curso "Brasil Hoje - conseqüências, limitações e perspectivas do processo de abertura”. O CEBRADE patrocinou com o Comitê Brasileiro pela Anistia (CBA), do qual Ênio também participava "o movimento pela libertação de Flavia Schilling, que teve como fato mais marcante a manifestação em frente ao consulado do Uruguai" ${ }^{2}$. A polícia conclui que o CEBRADE

(...)no seu trabalho de massa, buscando alcançar todos aqueles objetivos inicialmente expressos e ainda não atingidos, os quais são constantemente mencionados através de manifestações públicas e dos órgãos de comunicação social, sendo, os mais sensíveis e tenazmente perseguidos, a extinção de órgãos de informação e segurança, a revogação da lei de Segurança Nacional e a convocação de uma Assembléia Nacional Constituinte, com o que estará aberto o caminho para a legalização do Partido Comunista ${ }^{33}$.

Esse espaço cultural aberto com o CEBRADE constituiu-se em importante meio de ampliar a adesão para a luta democrática independentemente das diferentes tendências partidárias. A respeito dessas adesões, por outro lado, elas se mantiveram abertamente presentes nos debates. Em maio de 1979, por exemplo, o Comitê Central do PCB expôs a visão do partido sobre a não divisão da oposição e sobre a formação do PT, como segue:

Compreendemos a atitude das lideranças sindicais que se manifestam pela criação de um partido dos trabalhadores. Trata-se de um sintoma do nível político já alcançado pelo movimento sindical, de uma manifestação da justa compreensão já existente de que a luta apenas econômica não basta para resolver os problemas dos trabalhadores. Entretanto, queremos fazer ainda uma ressalva, sobre a qual é nosso dever não silenciar: a criação do projetado partido dos trabalhadores não deve envolver os sindicatos como tais; eles de- 
vem permanecer organizações classistas unitárias de todos os trabalhadores e, por isso mesmo, apartidárias. Pensamos que na origem da idéia de criar esse partido há um desencanto com o quadro partidário existente. Isso coloca a necessidade de uma maior sensibilidade do MDB aos problemas sociais. A luta pela democracia não pode ser desligada da luta pelo atendimento das reivindicações mais sentidas e urgentes dos trabalhadores e das massas populares ${ }^{34}$.

A discussão sobre a divisão da oposição se dava justamente a respeito das propostas nas duas direções apontadas no início do artigo: uma do "novo sindicalismo" e a outra em torno do $\mathrm{MDB}$, ambas visando à construção dos caminhos democráticos. Observamos que, Ênio Silveira ao fundar o CEBRADE se aproximou da direção que se organizava em torno do "novo sindicalismo", reconhecendo sua luta política mais ampla, como também ao entender que poderia haver uma ausência de "sensibilidade do MDB aos problemas sociais" e reconhece um limite daquele partido, sem, no entanto, comprometer seu apoio a este partido.

O que foi apresentado sobre a posição do editor Ênio Silveira na conjuntura política a partir dos textos dos editoriais da Encontros, se confirmou aqui por meio de outras referências permitindo qualificar o seu papel militante. As ações do editor-militante se firmaram ao final do regime na formação de uma frente de oposição contra a ditadura e na perspectiva democrática almejada pelo Partido Comunista Brasileiro (PCB) no pós-79, formalizada em seu apoio ao Partido do Movimento Democrático Brasileiro (PMDB).

\section{Coleção Primeiros Passos; "Universidade Aberta”; Amarelo das Diretas Já! e o Partido dos Trabalhadores nas ações de Caio Graco Prado}

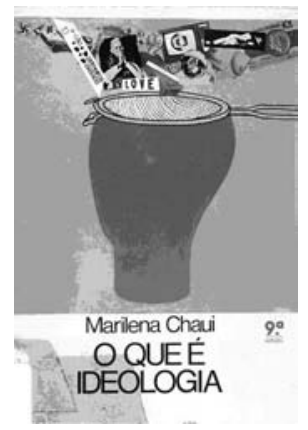

Figura 2. 
A publicação da "Coleção Primeiros Passos" inaugurou o lançamento dos livros de bolso da editora Brasiliense no âmbito de um projeto político-cultural conduzido pelo editor Caio Graco Prado. No início dos anos 1980, ele reivindicou a aproximação da Brasiliense com o público leitor jovem que o inspirou a criar a Coleção Primeiros Passos e promoveu outros lançamentos na mesma linha editorial, como foram os casos de: Cantadas Literárias, Tudo é História, Circo de Letras e Encanto Radical.

A juventude como público alvo da editora nesse momento foi aquele identificado pelo editor nos congressos da Sociedade Brasileira para o Progresso da Ciência (SBPC), quando estes se tornaram encontros de discussão política ampla, em fins da década de 1970, momento em que as áreas de ciências humanas e sociais passaram a ter uma participação mais significativa nesses congressos. A presença da Brasiliense no Congresso SBPC de 1979, em Fortaleza, correspondeu ao incremento das atividades de editoras cujas linhas de publicação contemplavam as áreas de humanas e sociais em seus estandes de vendas.

Desde a atenção às mudanças do cenário de grande movimentação política de estudantes até o reconhecimento da necessidade de aprofundamento dos discursos curiosos, porém simplificados, desses jovens, Caio Graco entendeu que havia um espaço de formação a ser preenchido.

A coleção Primeiros Passos foi criada com objetivo de ampliar e divulgar para um público maior o conhecimento sobre temas específicos relacionados aquele momento de abertura política. Com um texto em linguagem pouco acadêmica, mas buscando um conteúdo razoavelmente aprofundado, sob o título "O que é", a Coleção Primeiros Passos elegeu temas como capitalismo, socialismo, sindicalismo, dialética, política cultural, ideologia, nacionalidade, tortura, poder, cultura, revolução, ditadura, participação política, imperialismo, entre outros. Buscava-se assim estimular o interesse de um público jovem em saber mais sobre esses assuntos para poder melhor refletir sobre a própria conjuntura.

Os títulos foram solicitados pelo editor aos autores e, posteriormente, vários autores manifestaram-se e enviaram novas propostas ao editor. Segundo Yolanda Cerquinho Prado ${ }^{35}$, diretora-presidente da Brasiliense, o trabalho editorial de Caio Graco era realizado em parceria com Luis Schwarcz, na época funcionário da empresa, até sua saída em 1986, quando fundou sua própria editora, a Companhia das Letras.

O formato da Coleção Primeiros Passos foi inspirado, segundo Luiz Schwarcz ${ }^{36}$, em uma coleção de origem espanhola denominada Biblioteca de la Iniciación Política. Esta coleção fora recomendada por Carlos Knapp, um amigo de Caio Graco que, exilado na Espanha, conheceu a coleção e sugeriu à Brasiliense que comprasse os direitos de sua publicação para lançá-la no Brasil.

Os títulos temáticos daquela coleção, como "Que es capitalismo?" "Que es socialismo?" foram sugestivos para que Luiz Scwharcz, reponsável pela análise da coleção, desorientasse o editor Caio Graco a publicá-la no Brasil. Ao contrário, não deram prosseguimento ao acordo e o pagamento para compra dos direitos de publicação foram suspensos, entretanto, acordaram em investir no mesmo modelo de livro de bolso, mas com análises baseadas na realidade brasileira.

A seleção de autores para escrever os livros da Coleção foi realizada em torno daqueles intelectuais que circulavam no mesmo ambiente intelectual paulista. Os dados biográficos dos autores da Coleção Primeiros Passos entre os anos 1980 e 1985 mostraram a predomi- 
nância de formação acadêmica e atuação profissional realizadas em instituições paulistas, como a Universidade de São Paulo (USP), a Fundação Getulio Vargas de São Paulo (FGV/ $\mathrm{SP})$ e a Universidade Estadual de Campinas (Unicamp). Nas palavras de Schwarcz, os autores eram aqueles reunidos no espaço da editora Brasiliense, no "12..$^{\circ}$ andar da rua Barão de Itapetininga... (onde) as pessoas iam levar seus artigos e a gente acabava se reunindo". Tanto os autores convidados no início quanto os demais - os que enviavam textos para a seleção dos editores - constituíam a rede de relações construída em torno de uma certa intelectualidade paulista no período.

Os primeiros autores foram selecionados por Vanya Sant'Anna, ex-professora de ciência política de Luiz Schwarcz, sugerida por ele, para escrever os títulos sobre capitalismo, anarquismo, comunismo, socialismo e sindicalismo, mas também, buscaram intelectuais interessados na ampliação do debate político. Junto aos primeiros autores -como Afrânio Mendes Catani, Caio Tulio Costa, Arnaldo Spindel e Ricardo Antunes- os demais nomes formaram um conjunto de autores oriundos da intelectualidade paulista na maioria dos títulos da Coleção. Nesse sentido, intelectuais como Frei Beto, Caio Prado Junior, Marilena Chauí, Dalmo Dallari, Florestan Fernandes etc interessados na realização de debates conjunturais sobre temas sociais e preocupados com a participação política, com vistas ao fim da ditadura civil-militar brasileira, consolidavam a perspectiva crítica nos temas da coleção.

As temáticas divulgadas pela editora Brasiliense nos títulos da Coleção Primeiros Passos cumpria o papel de ligar assuntos da conjuntura nacional com temas universais. Ou seja, tratava das questões internas a partir do estímulo às leituras temáticas mais amplas oferecendo ao leitor, indiretamente, um determinado instrumental para análise da política do período. Foram tratadas questões sobre a política brasileira, mas não se detinham numa análise exclusiva de algum tema da história do Brasil. Por exemplo, no caso dos títulos "O que é Capitalismo", "O que é Sindicalismo", "O que é Socialismo", "O que é História”, "O que é Indústria Cultural”, primeiramente são abordadas questões da história desses temas na conjuntura internacional para depois tratá-los no Brasil. Desta forma a Primeiros Passos já apresentava uma diferença significativa em relação à coleção espanhola que a havia inspirado. Ao contrário da Biblioteca de la Iniciación Politica, os seus textos não propunham uma análise específica sobre o país, mas mostrava uma determinada perspectiva política geral que podia ser aplicada sobre a conjuntura.

Os resultados financeiros garantidos pela repercussão da coleção Primeiros Passos proporcionou o primeiro boom editorial da Brasiliense e assegurou à editora, entre os anos de 1980 e 1984, a venda de 2,5 milhões de exemplares, o que significava, na época, segundo Fernando Paixão (1998), 25\% de seu faturamento.

O sucesso dos livros foi garantido pela linguagem simples dos textos para apresentar temas relativamente complexos, mas também pelo seu formato. $\mathrm{O}$ modelo pequeno, com média de 90 páginas, como as chamadas edições de bolso, com capas ilustradas e, por vezes, charges de conhecidos cartunistas - nomes da imprensa alternativa dos anos 1970, como Paulo Caruso e Miguel Paiva - e com preços acessíveis, seu formato, assim, garantia que os livros da Coleção Primeiros Passos também fossem produtos de mais fácil venda. Em 1984 houve uma co-edição com a editora Abril visando a divulgação mais ampla nas bancas de jornal como pontos de venda da Coleção. Foi o caso, entre outros, do título $O$ 
que é participação política, lançado pela Brasiliense em 1983 e co-editado com a Abril em 1984. A concepção gráfica dos livrinhos era uma parte do processo de sua produção valorizada naquele momento pelas edições brasileiras. Em alguns títulos co-editados nota-se algumas diferenças de concepção sobre o próprio título proposto. (Lemos, 2003)

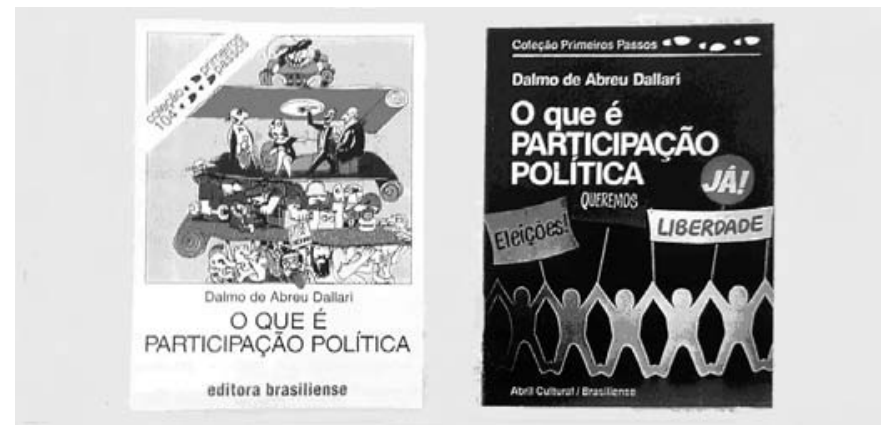

Figura 3.

As duas capas foram assinadas pelo mesmo ilustrador, Paulo Caruso, mas sua intenção em cada uma parece mais ligada ao exato momento de publicação, assumindo uma certa profissionalização para divulgação do título. Em 1984 era o momento de campanha pelas Diretas Já no país e a capa mostra uma pelo mais imediato pelas eleições diretas, ou ainda, uma estratégia de marketing adaptando-a ao acontecimento marcante daquele momento do que a uma concepção mais ampla para uma consciência política, como é abordado no texto. A capa antecessora, de 1983 -mesmo coincidindo com o contexto da proposta de emenda à Constituição em defesa das eleições diretas- apresentava pessoas de diversas classes sociais marcando uma concepção de participação mais ampla e diversificada, e não exclusivamente para as eleições.

As capas dos livros eram ilustradas de acordo com seu tema e ao final do texto havia indicações para leitura e uma biografia do autor que permitia ao leitor conhecer quem estava escrevendo. As reedições sucessivas lançadas pela editora expressariam o interesse de muitas pessoas sobre aqueles temas naquela conjuntura, e mostrariam também que a "Primeiros Passos" havia se tornado uma referência no mercado editorial brasileiro. Ela foi adotada em escolas e universidades e seu uso não se limitou àqueles anos, pois, ainda hoje, universitários, colegiais, professores e leigos em geral, consultam e compram a Coleção, parte deles disponibilizados recentemente em formato digital ${ }^{37}$.

O sucesso de vendas deveu-se, principalmente, pelos temas publicados em seu primeiro ano de lançamento. Com base na contagem das tiragens, seis dos títulos mais vendidos 
até 1985 foram aqueles publicados no primeiro ano de lançamento da Coleção. As primeiras edições de "O que é Ideologia", "O que é Capitalismo", "O que é Socialismo", "O que é Comunismo", “O que é Sindicalismo" e "O que é Questão Agrária” datam de 1980. Apenas dois desses títulos foram lançados em 1981: "O que é Educação" e "O que é Dialética”. Um deles foi publicado em 1982, “O que é Sociologia”; e outro em 1985, "O que é Constituinte". Ou seja, os maiores sucessos da Coleção durante seis anos de lançamentos concentraram-se nos temas escolhidos durante o seu primeiro ano de publicação. $\mathrm{O}$ título "O que é Ideologia", de Marilena Chauí, foi o de maior sucesso, alcançando entre 1980 e 1985 o número de 118.000 tiragens.

No contexto da abertura política consolidou-se a legitimação do editor Caio Graco Prado como empresário da cultura em adesão à ampla frente que se abriu pelo fortalecimento do movimento democrático brasileiro na década de 1980. Como editor, Caio Graco Prado foi capaz de reunir diferentes linhas políticas, desde intelectuais liberais até socialistas fora da esquerda tradicional em torno do partido comunista e de conquistar uma maior profissionalização ao papel do editor, quando exigia dos autores um texto menos acadêmico, interferindo com suas críticas à abordagem apresentada. Ao criar a coleção Primeiros Passos a editora Brasiliense concretizou por meio da ação do editor Caio Graco Prado estratégias de luta pelo conhecimento -estimulando a formação crítica e politizada- e imprimindo em sua função social organicidade ao processo de abertura democrática na ampliação da participação política necessária à sociedade brasileira. A ação política do editor ultrapassou a escolha de livros a publicar. Nesses anos da abertura democrática incentivou a campanha a favor das eleições diretas ao mesmo tempo em que direcionou sua adesão partidária pela criação do PT.

Caio Graco também criou nas livrarias da Editora Brasiliense novos espaços de discussão, ou seja, convidou professores, principalmente, e demais intelectuais para fazer palestras no interior da livraria. Estabeleceu assim uma relação mais direta destes profissionais da Universidade com o público que freqüentava a livraria atraindo, inclusive, novos clientes. Dessa forma, a editora criava um novo espaço cultural que corresponderia a uma "segunda livraria", porém, com um funcionamento bastante especial, pela sua nova atividade deixando de se limitar à venda de livros. Nas palavras de Caio Graco este novo espaço funcionaria como uma espécie de "universidade aberta". Dizia ele:

A Coleção Primeiros Passos sairá do papel impresso e se transformará, dentro da livraria, em aulas práticas para grupos de até 20 pessoas. É possível, portanto, ter Marilena Chauí, ao vivo, dissecando O que é Ideologia (seu best-seller na Coleção) ou o economista Paul Singer introduzindo os fundamentos da filosofia ${ }^{38}$.

Além das aulas houve também debates que ocorriam em frente à livraria na rua Barão de Itapetininga no centro de São Paulo. Segundo Marilena Chauí,

Em geral, falava o autor de um livro que estivesse sendo lançado. Ele falava durante uns 15 minutos sobre o livro e as pessoas -convidados e passantes-faziam perguntas ou emitiam opiniões. Era a idéia do Caio Graco de democrati- 
zar a cultura e de estimular a leitura de livros. Participava quem estivesse por lá: garis, sem-teto, estudantes, comerciários, professores, escritores, ambulantes ${ }^{39}$.

Essas "aulas" e debates constituíam-se também numa nova relação ou militância do professor universitário e dos estudantes de pós-graduação que escreveram para a coleção Primeiros Passos proporcionando um maior contato deles com os ouvintes para maiores discussões e atuações políticas. Era também uma forma de reunir "o pessoal da editora e sobretudo os encarregados da coleção Primeiros Passos para ouvir as idéias que os autores pretendiam desenvolver ou tinham desenvolvido nos livros" ${ }^{\prime 4}$. Essa aproximação facilitaria o momento em que "o pessoal da editora deveria ir aos meios de comunicação para falar dos livros e também os ajudava a orientar e escolher novos títulos, a partir de questões colocadas pelos títulos existentes" ${ }^{\prime 1}$. E, acrescenta-se, pelos seus autores, então, que há o reconhecimento de uma certa autoridade dos estudantes e profissionais da universidade, principalmente da USP, para a apresentação dos temas escolhidos para a coleção Primeiros Passos. Isso quer dizer também que houve a identificação desses autores com o projeto da editora, pois “... o fato de que uma ou mais de uma geração de escritores tenha certos interesses intelectuais e morais e não outros, tal fato indica que uma certa orientação intelectual predomina entre os intelectuais"42.

Apesar de não considerarem central naquele momento, o papel transformador da universidade, ela foi o principal canal de veiculação de ideias da Editora, e, principalmente, da Coleção, já que, conforme ficou demonstrado, havia um estreito vínculo dos autores com a universidade, assim como do público leitor.

Diante das novas formações partidárias do período, o editor da Brasiliense aderiu a formação do Partido dos Trabalhadores. Apesar de não se filiar ao Partido, ele se vinculou às campanhas políticas e aos movimentos culturais que promoviam a repercussão das idéias do PT daquele momento o que o tornou um dos "empresários no PT" ${ }^{43}$. Segundo Marilena Chaú, "Caio Graco foi um dos fundadores do PT e, juntamente com Carlito Maia, foi coordenador das campanhas de Suplicy para prefeito, governador e senador. Era ativíssimo no Diretório Municipal de São Paulo" ${ }^{44}$. Esta vinculação pode ser observada, ainda, no comentário do presidente nacional do PT na época, Luís Inácio Lula da Silva, quando da morte do editor, anos mais tarde. Ele afirmou: "O Brasil perde o mais moderno de seus editores. Perdemos um importante companheiro do PT"45.

Essa relação da Editora com o Partido dos Trabalhadores pode ser melhor identificada pelo apoio às idéias de esquerda, que circulavam em torno do partido e também quando da sua vinculação política e cultural a ele, incentivando a sua formação, e não apenas pela identificação de seu editor numa lista de filiados do partido.

É nesse quadro que as iniciativas de Caio Graco, em seu espaço editorial, coincidem com o debate mais amplo que ocorria na sociedade brasileira em prol de um movimento democrático. Verificou-se nas iniciativas do editor o estímulo à organização política e partidária da esquerda, pois além da Editora publicar, ao longo de sua trajetória, títulos e autores importantes para o pensamento de esquerda e nesse momento ter participado da formação do PT, Caio Graco lançou a cor amarela como cor-símbolo do movimento pelas eleições diretas para presidente, denominado Diretas-já. Em matéria na Folha de São Paulo, Caio Graco dizia que: 
A idéia do uso do amarelo para simbolizar a vontade popular pelas 'diretas já', ele conta ter surgido em janeiro, quando assistia a um telejornal, que mostrava o povo das Filipinas empregando a cor amarela para mostrar que era contra o presidente Ferdinand Marcos. Na reunião do Comitê pró-diretas discutiu-se o lançamento da cor amarela e questionando se não deveria ser verde Graco afirmou: "o verde a gente usa impunemente, por acaso. O amarelo não. Chama mais atenção, é menos comum e a gente pensa antes de usá-lo. Além do mais, é a cor da sabedoria na filosofia oriental ${ }^{46}$.

O forte apoio à campanha das "Diretas Já" remete, novamente, ao peso das eleições para o processo democrático naquele momento, ou melhor, da ênfase que lhe foi dada pelos diversos setores, inclusive do editor e dos intelectuais da editora Brasiliense ao divulgarem a cor amarela como símbolo desse movimento.

O período de produção da coleção "Primeiros Passos" coincide com o chamado processo de democratização. É justamente nesse período que a sociedade brasileira, como foi apresentado, em seus diversos setores ampliou significativamente suas formas de participação política. Entende-se, então, que a Editora construiu seu envolvimento junto às lutas da esquerda incentivando os debates nas ruas e na campanha das "Diretas Já" e, por outro lado, abria a possibilidade de uma produção em escala maior, voltada para esse público. Conclui-se que a participação do editor se caracterizou como empresário simpatizante das lutas dos movimentos sociais e políticos dos trabalhadores, inclusive em prol da formação do PT, principalmente na candidatura de Eduardo Suplicy, mas seu reconhecimento se deu, sobretudo, no sucesso da Coleção "Primeiros Passos", nas escolhas de temas, autores e percepção da demanda do público leitor. Sua participação como incentivador cultural na promoção de debates políticos permitiu ao editor imprimir, em sua função de publicar livros, uma perspectiva militante em prol da democratização.

Esse artigo dá ênfase às atuações de empresários da cultura vinculados a tais vertentes políticas e comprometidos com a participação na construção do processo de abertura democrática. Analisamos o papel de Caio Graco e Ênio Silveira como editores capazes de atribuir a seus papéis empresariais uma participação política de adesão aos debates da esquerda intelectual brasileira nos caminhos pela redemocratização pós-79 - inaugurando novas estratégias editoriais, novas apropriações dos espaços culturais e estabelecendo vínculos com setores da esquerda partidária.

A proposta de indicar o editor como organizador da cultura resgata o papel do editor numa perspectiva político-cultural mais ampla, capaz de ultrapassar sua função estrita da escolha da obra a se tornar pública, e mesmo não a dispensando, o editor passa a ser identificado como aquele que incentiva e promove o debate intelectual e político, também por meio de outras ações político-culturais, que expressam o quadro mais amplo de sua inserção cultural e social em certo momento histórico. 


\section{Notas}

1. Este artigo retoma, em partes e com modificações, minhas reflexões oriundas das pesquisas de mestrado e doutorado, respectivamente intituladas: 1) Andréa Lemos Xavier. A produção da Coleção Primeiros Passos: um projeto político-cultural da editora Brasiliense (1979-1985). Dissertação (Mestrado em História). Pontifícia Universidade Católica/PUC, Rio de Janeiro, 2003 e 2) Andréa Lemos Xavier Galucio. Civilização Brasileira e Brasiliense: trajetórias editoriais, empresários e militância política. Tese (Doutorado em História), Universidade Federal Fluminense/UFF, Niterói, 2009.

2. Lula: entrevistas e discursos, p. 45. Citado por MATTOS, Marcelo Badaró. Trabalhadores e sindicatos no Brasil. Rio de Janeiro: Vício de Leitura, 2002, p. 79.

3. A fundação de cada partido ocorreu: PCB(1922); PCdoB (1962, dissidência do PCB) e MR-8 (1966, dissidência do PCB).

4. Publicada entre 1965-68 e proibida de circular como AI-5 em 1968. Ver mais a respeito em: Lemos, Andréa. Revista Civilização Brasileira: resistência cultural à ditadura. In: Sandra Reimão (org.). Livros e subversão: seis estudos. São Paulo: Ateliê Editorial, 2016, v.1, pp. 91-118.

5. Ibidem.

6. Editorial, n.2, ago/1978, Ênio Silveira (diretor-responsável) - Fazer História ou Não, Eis a Opção.

7. Editorial, n.3, set/1978, Moacyr Felix (editor-chefe) - Raciocinar é uma coisa, Pensar é outra, p. 8 e 9 .

8. Editorial, n.4, out/1978, Moacyr Felix (editor-chefe) - Dezoito Parêmias do Verão Contraditório, p. 7.

9. Editorial, n.6, dez/1978, Ênio Silveira (diretor-responsável) - Apresentação: Quem Tapa o Sol com a Peneira?, p. 7.

10. Ibidem, p. 8.

11. Ibidem, p. 8.

12. Ibidem, p. 8 .

13. Ibidem, p. 9.

14. Ibidem, p. 9.

15. Ibidem, p. 10.

16. A primeira lista de adesões ao Centro Brasil Democrático contém os seguintes nomes: Alceu Callado (numa clara confusão entre os escritores Alceu Amoroso Lima e Antonio Callado), Antonio Candido, Barbosa Lima Sobrinho, Caio Prado Junior, Carlos Scliar, Chico Buarque de Holanda, Cláudio Abramo, Dalmo Dallari, Dias Gomes, Flavio Rangel, Fernando Santana, Francisco Pinto, Hélio Bicudo, Hélio Silva, Franklin de Oliveira, João Antonio, João Saldanha, Joaquim Pedro de Andrade, José Honório Rodrigues, Juca de Oliveira, Mário Lago, Mário Magalhães da Silveira, Mário Pedrosa, Maurício Roberto, Nelson Werneck Sodré, Nise da Silveira, Odilon Batista, Osny Duarte Pereira, Oswaldo Loureiro, Paulo Vanzolini, Plínio Marcos, Pompeu de Souza, Raul Riff, Rômulo de Almeida, Ruth Scobar, Terezinha Zerbini, Tiago de Melo e Zelito Viana. DOPS- DGIE 299, 1980, fl. 57. 
17. O episódio da bomba foi a motivação para mais esta investigação, bem detalhada, das funções, membros e atividades do CEBRADE, no período de 1978 até o ano do ocorrido, 1981.

18. DGIE 299, 1980, fl. 57. Arquivo Público do Estado do Rio de Janeiro (APERJ).

19. DGIE 273, 1978, fl. 10 D. Arquivo Público do Estado do Rio de Janeiro (APERJ).

20. O CGTI foi um "órgão de frente comunista, ligado ao CGT, que abrigou em seus quadros escritores, jornalistas, cientistas, artistas e professores para atuação nos meios intelectuais, inclusive nas escolas de nível médio e superior”. DOPS/RJ - DGIE 299, 1981, fl. 2. 21. DGIE, 1981, fl. 2. Arquivo Público do Estado do Rio de Janeiro (APERJ).

22. Palavras do Manifesto de Fundação do CEBRADE, citado em DGIE 299, 1981, fl. 2.

23. Cartilha redigida por um dos intelectuais em adesão ao manifesto do CEBRADE, Renato Guimarães Cupertino. DGIE 299, fl. 2.

24. Trecho do Manifesto do CEBRADE citado pela policia. DGIE, 299, fl. 2. Arquivo Público do Estado do Rio de Janeiro (APERJ).

25. DGIE 299, 1981, fl. 3. Arquivo Público do Estado do Rio de Janeiro (APERJ).

26. O CEBRADE era formado por 5 Conselhos: Diretor; Consultivo; Fiscal; de Defesa dos Direitos Humanos; de Credenciais. Ênio Silveira era vice-presidente junto com Sergio Buarque de Holanda do Conselho Diretor, Oscar Niemeyer era o presidente; Antonio Houaiss, secretário geral; Mauro Lins e Silva, tesoureiro; Audálio Dantas, Darcy Ribeiro, Dias Gomes, Francisco de Oliveira, Francisco Pinto e João Saldanha, como diretores. DGIE, 299, 1981, fl. 375.

27. DGIE 299, 1981, fl. 3.

28. DGIE 299 1981, fls. 4 e 5.

29. DGIE 299 1981, fl. 6.

30. DGIE 299, 1981, fl.1.

31. DGIE 299, fl. 6.

32. DGIE, fl. 6.

33. DGIE 299, 1981, fl. 8 .

34. PCB: vinte anos de política, 1958-1979 (documentos). São Paulo: Livraria e Editora Ciências Humanas, 1980, (A Questão Social no Brasil, v. 7), p. 325.

35. Yolanda Cerquinho Prado em entrevista a autora em outubro de 2001.

36. Luis Schwarcz em entrevista a autora em outubro de 2002.

37. http://www.netmundi.org/home/2017/40-livros-da-colecao-primeiros-passos-parabaixar/

38. GRACO, Caio. Novo espaço da Brasiliense. Rio de Janeiro: Jornal do Brasil, Seção Livro, 26/06/1984.

39. Marilena Chauí em entrevista à autora em agosto de 2003.

40. Ibidem.

41. Ibidem.

42. GRAMSCI, Antonio. Literatura e Vida Nacional. Rio de Janeiro: Civilização Brasileira, 1968, p. 15.

43. Yolanda Prado em entrevista à autora em outubro de 2001.

44. Marilena Chaú em entrevista à autora em agosto de 2003.

45. CAIO Graco: vítima de uma paixão. Rio de Janeiro: Jornal do Brasil, 19/06/1992. 
46. CAIO Graco, o homem do amarelo, crê nas diretas. São Paulo: Folha de São Paulo, 19/04/1984.

\section{Referências}

Almeida, Gelson Rozentino de Almeida (2000). A história de uma década quase perdida: 19791989. Tese (Doutorado em História), Universidade Federal Fluminense, Rio de Janeiro. Bourdieu, P. (1996). Razões Práticas: sobre a teoria da ação. Campinas: Papirus.

Chartier, R. y Roche. (1976). "O livro: uma mudança de perspectiva”. In LE GOFF, Jacques; NORA, Pierre (Orgs.). História: novos objetos. Rio de Janeiro: Francisco Alves.

Chauí, M. (1986). Conformismo e Resistência. São Paulo: Brasiliense.

Coutinho, C. (2000). CCC ultura e Sociedade no Brasil: Ensaios sobre idéias e formas. 2 ed. Rio de Janeiro: DP\&A.

Dreifuss, R. (1981). 1964 - A Conquista do Estado: ação política, poder e golpe de classe. Rio de Janeiro: Vozes.

Gramsci, A. (1968). Literatura e Vida Nacional. Rio de Janeiro: Civilização Brasileira.

Gurgel, C. (1989). Estrelas e Borboletas: PT - Origens e questões de um partido a caminho do poder. Rio de Janeiro: Papagaio.

Lemos, A. (2016). Revista Civilização Brasileira: resistência cultural à ditadura. In: Sandra Reimão (org.). Livros e subversão: seis estudos. São Paulo: Ateliê Editorial.

Lemos, A. (2010). Ênio Silveira: o empresário militante. In: Marcelo Badaró Mattos (org.).Livros vermelhos: literatura, trabalhadores e militância no Brasil. Rio de Janeiro: Bom Texto; FAPERJ.

Mattos, M. B. (2002). Trabalhadores e sindicatos no Brasil. Rio de Janeiro: Vício de Leitura. Mendonca, S. R. De. (1996). História do Brasil Recente-1964-1992. São Paulo: Ática, 1996. (Coleção Princípios).

Miceli, S. (1989). Estado e Cultura no Brasil. São Paulo: Difel, 1984.

Moraes, D. de. (1989). A Esquerda e o golpe de 1964. Rio de Janeiro: Espaço e Tempo.

Napolitano, M. (2006). Cultura Brasileira: utopia e massificação (1950-1980). 3 ed. São Paulo: Contexto.

Paixao, F. (1998). Momentos do Livro no Brasil. São Paulo: Ática.

PCB: vinte anos de política, 1958-1979 (documentos). São Paulo: Livraria e Editora Ciências Humanas, 1980, (A Questão Social no Brasil, v. 7).

Santana, M. A. (2003). Trabalhadores em movimento: o sindicalismo brasileiro nos anos 1980-1990. p. 293. In: FERREIRA, Jorge; DELGADO, Lucilia (Org.). O tempo da ditadura: regime militar e movimentos sociais em fins do século XX. Rio de Janeiro: Civilização Brasileira, 2003, (O Brasil Republicano, v. 4).

Silveira, E. (1978). Por quê e para quê. Encontros com a Civilização Brasileira, n.1,1978, p.7. Sorj, B. (2001). A construção intelectual do Brasil contemporâneo - da resistência à ditadura ao governo FHC. Rio de Janeiro: Jorge Zahar. 
Resumen: Los espacios culturales creados por las casas editoriales brasileñas, comprometidas con el proceso de reanudación de las condiciones democráticas en Brasil a fines de los años setenta y principios de los ochenta, fueron mucho más allá de las rigurosas elecciones de autores, temas y nuevos formatos de libros en sus catálogos. Al construir medios para ampliar la participación política de la intelectualidad brasileña en nuevos espacios culturales al final de la dictadura civil-militar, editores como Caio Graco Prado (Brasiliense) y Enio Silveira (Civilização Brasileira) continuaron sus prácticas político-culturales de resistencia al régimen militar e intervención en el proceso formativo de lectores interesados en una mayor politización.

Palabras clave: Historia editorial - Colecciones - Editores brasileños - Democracia - Redemocratización - Resistencia.

Abstract: The cultural created by Brazilian Publishing companies, committed to the process of the redemocratization in Brazil in the late 1970s and early 1980s, went far beyond rigorous choices of aurhors, themes, and new book formats in their catalogs. By building means of broadening the political participation of the Brazilian intelligentsia in new cultural spaces at the end of the civil-military dictatorship, publishers such as Caio Graco Prado (Brasiliense) and Enio Silveira (Civilizacao Brasileira) continued their politicalcultural practices of resistance to the military regime and practices or intervention in the formative process of a reder interested in greater politicization.

Keywords: Publishing History - Collections - Brazilian publishers - Democracy - Redemocratization - Resistance.

[Las traducciones de los abstracts fueron supervisadas por el autor de cada artículo] 